\section{Tendência dos acidentes de trânsito em Campinas, São Paulo, Brasil: importância crescente dos motociclistas}

\author{
Trends in traffic accidents in Campinas, \\ São Paulo State, Brazil: the increasing \\ involvement of motorcyclists
}

1 Faculdade de Ciências Médicas, Universidade Estadual de Campinas, Campinas, Brasil. 2 Secretaria Municipal de Saúde de Campinas, Campinas, Brasil.

Correspondência L. Marín-León Departamento de Medicina Preventiva e Social, Faculdade de Ciências Médicas, Universidade Estadual de Campinas.

Rua Tessalia Vieira de Camargo 126, Cidade Universitária, Campinas, $S P$ 13083-887, Brasil leticia@fcm.unicamp.br

\begin{abstract}
In order to describe trends in traffic accidents, mortality, vehicle types, fleet sizes, and victims' characteristics in Campinas, São Paulo State, Brazil, from 1995 to 2008, this study analyzed vehicle rates, traffic accident rates per inhabitant and per vehicle, case-fatality rates, proportional mortality, mortality rates, and rates ratios. The motorcycle fleet increased $241 \%$. Although the case-fatality rate of motorcycle users from 2000 to 2008 decreased, in 2008 they accounted for $49.3 \%$ of fatal accidents on public byways in Campinas. Motorcycles were responsible for the highest runover rate (66.7 pedestrians/1,000 accidents) and highest pedestrian fatality rate ( 4 deaths/1,000 accidents). Men showed much higher mortality rates than women. Pedestrian victims were mainly elderly; most vehicle occupants in traffic accidents were in the 15 to 29-year age bracket. From 2006 to 2008, nearly 80\% of vehicle users 15 to 39 years of age were motorcyclists. Motorcycle accident prevention should be a priority, using multi-institutional measures.
\end{abstract}

Traffic Accidents; Motorcycles; Mortality
Leticia Marín-León 1

Ana Paula Belon 1

Marilisa Berti de Azevedo Barros 1

Solange Duarte de Mattos Almeida 2

Maria Cristina Restitutti 2

\section{Introdução}

Os acidentes de trânsito constituem um problema importante para a saúde pública em virtude do grande impacto na morbidade e mortalidade, principalmente da população jovem do sexo masculino ${ }^{1}$. Segundo estimativas da Organização Mundial da Saúde (OMS) 2, por ano, é registrado no mundo cerca de 1,2 milhão de mortes no trânsito, o que representa um total de três mil mortes por dia. O Brasil está entre os dez países que concentram mais de $60 \%$ dos óbitos por acidentes de trânsito ${ }^{3}$.

Nos países desenvolvidos, a tendência de mortalidade por estes agravos é de declínio 2,3,4. Em estudo sobre a mortalidade por acidentes de trânsito na Noruega, Suécia, Dinamarca, Finlândia, Países Baixos, Grã-Bretanha, Austrália e Estados Unidos entre 1997 e 2007, registrou-se tendência decrescente do número de óbitos por esta causa, embora tal redução seja irregular, oscilando entre períodos de estagnação e mesmo de crescimento ${ }^{4}$. No entanto, nos países em desenvolvimento, as estimativas de mortalidade por acidentes de trânsito, além de serem superiores às dos países desenvolvidos, têm apresentado aumento desde a década de 1990 2,3. A magnitude dessa fatalidade nestes países é identificada, ainda, pelo fato de que $85 \%$ das mortes por acidentes de trânsito se concentram nas regiões em desenvolvimento 2 . 
As estatísticas de mortalidade recentes mostram que, nos países de maior renda, a taxa de mortalidade é de 10,3 óbitos por 100 mil habitantes, ao passo que, nos países de média e baixa renda, os coeficientes são de 19,5 e 21,5 óbitos por 100 mil habitantes, respectivamente 3 . Essas desigualdades se expressam, também, nos indicadores calculados para cada país: no Japão, a taxa de mortalidade por acidentes de trânsito já atingiu o patamar de 5,0 mortes em 100 mil habitantes; na Grã-Bretanha, o índice é de 5,4; na Alemanha, 6,0; no Canadá, 8,8 3. Por sua vez, no México, a estimativa é de 20,7 e, na Argentina, de 13,7 óbitos por 100 mil habitantes ${ }^{3}$. Para o Brasil, a taxa de mortalidade por esta causa é de 18,3 óbitos por 100 mil habitantes ${ }^{3}$.

No Brasil, as publicações da OMS 3 e do Ministério da Saúde 5 apresentam o crescimento dos indicadores de morbidade e mortalidade relacionados aos acidentes de trânsito nos últimos anos. Em publicação sobre desigualdades na mortalidade por acidentes de trânsito, o Ministério da Saúde 6 alertou para o impacto negativo destes sobre a saúde da população brasileira, a perda de anos de vida livres de incapacidade, a redução da expectativa de vida dos adolescentes e jovens, além dos altos custos sociais e econômicos impostos ao sistema de saúde e previdenciário.

Apesar da implantação do Código Nacional de Trânsito, em 1998, com o estabelecimento de normas legais para punir os infratores, e da Lei Seca 7, em 2008, revisando o limite do consumo de bebida alcoólica por condutores, os acidentes de trânsito ainda representam uma importante causa de mortalidade precoce e evitável no Brasil. Países que têm implantado com êxito medidas de regulamentação, fiscalização e educação vêm apresentando taxas muito menores de óbitos por essa causa $8,9,10$.

Outro aspecto importante da realidade brasileira é o expressivo crescimento da frota de motocicletas, com aumento de $61 \%$ do licenciamento desse meio de transporte entre 2002 e 2006 11,12. Esse crescimento foi apoiado por políticas federais que favoreceram a fabricação, o baixo custo e o financiamento desses veículos e pode estar relacionado ao aumento das mortes com motocicletas no Brasil, as quais passaram de $3 \%$ para $27 \%$ dos óbitos por acidentes de trânsito entre 1996 e 200611.

Como as motocicletas tornaram-se muito usadas na entrega de pequenas mercadorias, vários autores 13,14,15 apontam que a pressão de empregadores e clientes por rapidez nesse serviço é fator importante na ocorrência de acidentes de trânsito nesta categoria e que, portanto, a organização do trabalho deve ser considerada nas intervenções de prevenção ${ }^{16}$. Além do uso da moto como instrumento de trabalho, $75 \%$ da frota é usada para deslocamento ao trabalho ou estudo em virtude de sua rapidez 17 . A proibição de circulação de motocicletas entre filas de veículos de quatro rodas em movimento, proposta para integrar o Código de Trânsito em vigor desde 1998, foi vetada pelo Poder Executivo, mesmo que esta condição seja, provavelmente, a principal causa de morte dos motociclistas nas grandes cidades 17 .

Inserido na preocupação de formular políticas públicas integradas e intersetoriais para o melhor enfrentamento do problema dos acidentes de trânsito, foi estabelecida uma parceria entre o meio acadêmico, a Secretaria de Saúde e a Secretaria de Transporte (SETRANSP) representada pela Empresa Municipal de Desenvolvimento de Campinas (EMDEC), a fim de avaliar a violência no município, ampliando assim as dimensões de análise relativas a estes eventos. Essa produção intersetorial, que procura realizar o monitoramento da tendência do perfil da morbidade e mortalidade por acidentes de trânsito, oferece um importante conjunto de dados para a gestão do sistema de trânsito e de saúde, podendo apoiar e orientar medidas públicas de prevenção e controle desse tipo de violência.

Diante do exposto, o objetivo do presente estudo é descrever a tendência das ocorrências dos acidentes de trânsito e da mortalidade por esta causa, abordando questões relacionadas ao tamanho da frota, ao tipo de veículo envolvido, ao perfil das vítimas fatais e não fatais sendo também apresentada a distribuição espacial dos eventos no Município de Campinas, Estado de São Paulo.

\section{Métodos}

Trata-se de um estudo descritivo sobre acidentes de trânsito, para o qual foram empregados dados secundários do período de 1995 a 2008. As informações de mortalidade foram obtidas do Sistema de Informações sobre Mortalidade (SIM); as de ocorrências e frota da SETRANSP, por meio da EMDEC; e as estimativas populacionais do Instituto Brasileiro de Geografia e Estatística (IBGE; http://www.ibge.gov.br).

Com os dados da EMDEC, foram estimadas taxas de motorização (veículos em cem habitantes), taxas de ocorrência de acidentes de trânsito por habitante e por veículo, bem como proporção de acidentes com vítimas e vítimas atropeladas, em relação ao conjunto de acidentes. Foram ainda construídos indicadores de razão de mortalidade proporcional e de letalidade segun- 
do tipo de vítima fatal. Para cada tipo de veículo envolvido no acidente, foram estimadas taxas de ocorrência de vítimas não fatais e coeficientes de letalidade para o ano de 2008. Foram calculadas razões entre as taxas, visando apontar a magnitude das diferenças dos acidentes de trânsito, segundo tipo de veículo.

No sistema de informações da EMDEC, estão registrados todos os acidentes de trânsito ocorridos em Campinas, independentemente do município de residência da vítima. No entanto, como as várias rodovias que cortam o município de Campinas não integram a área de jurisdição da EMDEC, os óbitos ocorridos nessas vias não são coletados por esta fonte de dados.

Portanto, foram utilizados óbitos por residência do SIM (1995-2008) do Departamento de Informática do SUS (DATASUS; http://www. datasus.gov.br), para o cálculo de mortalidade proporcional e coeficientes de mortalidade por acidentes de trânsito dos residentes em Campinas, com o propósito de descrever o perfil das vítimas fatais. Para o cálculo dos coeficientes de mortalidade, foram utilizados dados da população residente em Campinas no denominador. Para o ano de 1995, foram incluídos os óbitos com causa básica E810-E819 da 9a revisão da Classificação Internacional de Doenças (CID-9). A partir de 1996, período em que passa a vigorar a 10a versão (CID-10), foram usados os códigos de V01 a V89. Também foi estimada a razão de mortalidade proporcional por tipo de veículo não especificado (V89), que constitui um indicador de qualidade inadequada do registro dos veículos envolvidos no acidente.

Ainda com os dados do SIM da Secretaria Municipal de Saúde, realizou-se o georreferenciamento pontual dos locais de ocorrência de todos os acidentes de trânsito fatais acontecidos no Município de Campinas, nos anos de 2006 e 2007, independentemente do município de residência. Foram produzidos mapas de densidade para o reconhecimento visual de áreas com maior concentração de pontos, por meio do estimador de densidade Kernel 18, considerando separadamente os acidentes de trânsito fatais ocorridos nas rodovias e nas vias públicas municipais. Para o georreferenciamento, foram utilizados o programa MapInfo Professional (MapInfo Corp., New York, Estados Unidos) e as bases digitais de logradouros, bairros e áreas de abrangência de Centros de Saúde de Campinas. A análise da distribuição espacial pela técnica de Kernel foi realizada por intermédio do programa ArcGIS (http:// www.esri.com/software/arcgis/index.html) e sua extensão Spatial Analyst, utilizando-se a função quadrática de suavização dos pontos e largura de banda de $1 \mathrm{~km}$, a qual se mostrou mais adequada às características dos eventos analisados e aos objetivos deste estudo.

\section{Resultados}

Entre 1995 e 2008, Campinas experimentou um importante crescimento da frota de veículos; sendo que a taxa de motorização passou de 39 para 61 veículos por cem habitantes (Tabela 1). O aumento da frota de motocicletas foi ainda mais expressivo, passando de três para nove motos por cem habitantes neste mesmo período. O percentual de ocorrência de acidentes com vítimas foi de $19,3 \%$ em 1995 , tendo aumentado para $24,8 \%$ em 2008. No período analisado, o percentual de atropelamentos, que era de 5,6\% em 1995, diminuiu para 4,3\% em 2008. Entre 1995 e 2008, houve mudança do tipo de vítima fatal: as mortes dos pedestres diminuíram de 55,3\% para $29,7 \%$, enquanto as de ocupantes de moto aumentaram de $6,6 \%$ para $49,3 \%$ no conjunto total de óbitos. A letalidade relacionada às vítimas de atropelamento, embora maior que a registrada pelos ocupantes de veículos, diminuiu de dez para 4,7 mortes em cada cem atropelamentos entre o início e o fim do período. Já a letalidade referente aos motociclistas foi mais elevada que a de pedestres, tanto em 2000, como em 2005 e 2008.

Quanto aos ocupantes de veículos, os coeficientes de mortalidade dos residentes de Campinas decresceram e alcançaram o menor valor no sexo masculino em 2005; contudo, no ano posterior, a mortalidade passou a aumentar, atingindo, em 2008, 24,6 óbitos por 100 mil habitantes (Tabela 1). O risco de homens morrerem por acidentes de trânsito foi sempre maior que o de mulheres. Em 2008, morreram 8,2 e 3,6 homens para cada mulher entre ocupantes de veículos e pedestres, respectivamente. Entre 1995 e 2000, no sexo masculino, a mortalidade de ocupantes de veículos e de pedestres sofreu redução de 32,3\% e $48,9 \%$, respectivamente. No entanto, no período de 2000 a 2008, há novo aumento dos coeficientes de mortalidade por acidentes de trânsito, sem atingir os valores de 1995.

Apesar do aumento da frota de veículos e do tamanho da população, na Figura 1 observa-se que as taxas de ocorrência de acidentes diminuíram entre 1999 e 2003, tanto em relação à frota (39,1\%) e quanto à população (34,5\%). Esta taxa, que, em 1997, era de 52,1 acidentes por mil veículos, atingiu o menor índice em 2003, passando para 29,6. Em relação à população, a taxa declinou de 22,4 para 14,6 acidentes por mil habitantes. A partir de 2004, essas taxas sofreram aumento, registrando, em 2008, 30,1 acidentes por mil veículos e 18,4 acidentes por mil habitantes, isto 
Tamanho da frota de veículos e indicadores de mortalidade por acidentes de trânsito. Campinas, São Paulo, Brasil, 1995, 2000, 2005 e 2008.

\begin{tabular}{|c|c|c|c|c|}
\hline Variáveis e categorias & 1995 & 2000 & 2005 & 2008 \\
\hline \multicolumn{5}{|l|}{ Frota } \\
\hline Total de veículos & $352.000 *$ & 454.490 & 523.416 & 647.059 \\
\hline Motocicletas (n) & $27.000 *$ & 39.913 & 60.861 & 92.108 \\
\hline Motocicletas (\%) & 7,7 & 8,8 & 11,6 & 14,2 \\
\hline \multicolumn{5}{|l|}{ Taxas de motorização } \\
\hline Relação veículo/100 habitantes & 38,8 & 46,9 & 50,1 & 61,2 \\
\hline Relação moto/100 habitantes & 3,0 & 4,1 & 5,8 & 8,7 \\
\hline Percentual de acidentes com vítimas & 19,3 & 18,0 & 23,9 & 24,8 \\
\hline Percentual de acidentes com vítimas atropeladas & 5,6 & 4,3 & 4,5 & 4,3 \\
\hline \multicolumn{5}{|l|}{ Distribuição relativa do tipo de vítima fatal (\%) } \\
\hline Pedestres & 55,3 & 29,5 & 36,4 & 29,7 \\
\hline Ocupantes de motocicletas & 6,6 & 33,0 & 35,2 & 49,3 \\
\hline Ocupantes de outros veículos (exclui motos) & 38,1 & 37,5 & 28,4 & 21,0 \\
\hline \multicolumn{5}{|l|}{ Letalidade segundo tipo de vítima (por 100 acidentes } \\
\hline \multicolumn{5}{|l|}{ com vítimas) } \\
\hline Pedestres & 10,0 & 4,0 & 4,1 & 4,7 \\
\hline Ocupantes de motocicletas & $-\star \star \star$ & 32,3 & 15,5 & 23,8 \\
\hline Ocupantes de outros veículos (exclui motos) & 3,3 & 2,8 & 1,9 & 2,6 \\
\hline \multicolumn{5}{|l|}{ Coeficientes de mortalidade padronizados } \\
\hline \multicolumn{5}{|l|}{ (por 100 mil habitantes) } \\
\hline \multicolumn{5}{|l|}{ Homens } \\
\hline Ocupantes de veículos & 30,0 & 20,3 & 19,8 & 24,6 \\
\hline Pedestres & 13,7 & 7,0 & 5,7 & 9,8 \\
\hline \multicolumn{5}{|l|}{ Mulheres } \\
\hline Ocupantes de veículos & 4,0 & 4,8 & 4,8 & 3,0 \\
\hline Pedestres & 4,2 & 1,2 & 5,6 & 2,7 \\
\hline
\end{tabular}

Fonte: Empresa Municipal de Desenvolvimento de Campinas (EMDEC), 1995-2008; Sistema de Informações sobre Mortalidade (SIM) do Departamento de Informática do SUS (DATASUS; http://www.datasus.gov.br), 1995-2008.

* Dados estimados;

** Em 1995, não há registro discriminado dos motociclistas.

é, um aumento de $1,7 \%$ e $26 \%$, respectivamente, em comparação com 2003.

Na Figura 2, são apresentadas as taxas de vítimas e vítimas fatais a cada mil acidentes, segundo tipo de veículo envolvido, em 2008, nas vias públicas municipais. De cada mil acidentes que envolveram motos, 685 deles provocaram vítimas, observando-se 3,6 vítimas motociclistas para cada vítima ocupante de automóvel. O coeficiente de acidentes com vítimas fatais foi maior também naqueles que envolveram motos, com 7,1 óbitos de motociclista para cada óbito de ocupante de automóvel. Houve 66,7 vítimas atropeladas por motocicletas a cada mil acidentes envolvendo esse tipo de veículo. Observam-se, ainda, 3,4 atropelamentos por motocicleta para cada atropelamento por automóvel. Em cada mil acidentes que envolveram motos, quatro ocasionaram a morte de pedestres, tendo ocorrido 6,7 óbitos de pedestres atropelados por motociclista a cada atropelamento fatal por automóvel. Entre os atropelamentos por ônibus, verificaram-se 2,5 mortes de pedestre em cada mil acidentes que envolveram esse tipo de veículo.

Na Figura 3, no que diz respeito aos indivíduos do sexo masculino, quando os acidentes de trânsito foram estratificados em mortes de pedestres e de ocupantes de veículos, observou-se que, nos atropelamentos, os idosos são as principais vítimas fatais em todo o período, ao passo que a mortalidade de ocupantes de veículos foi mais elevada entre os jovens de 15 a 29 anos. No 

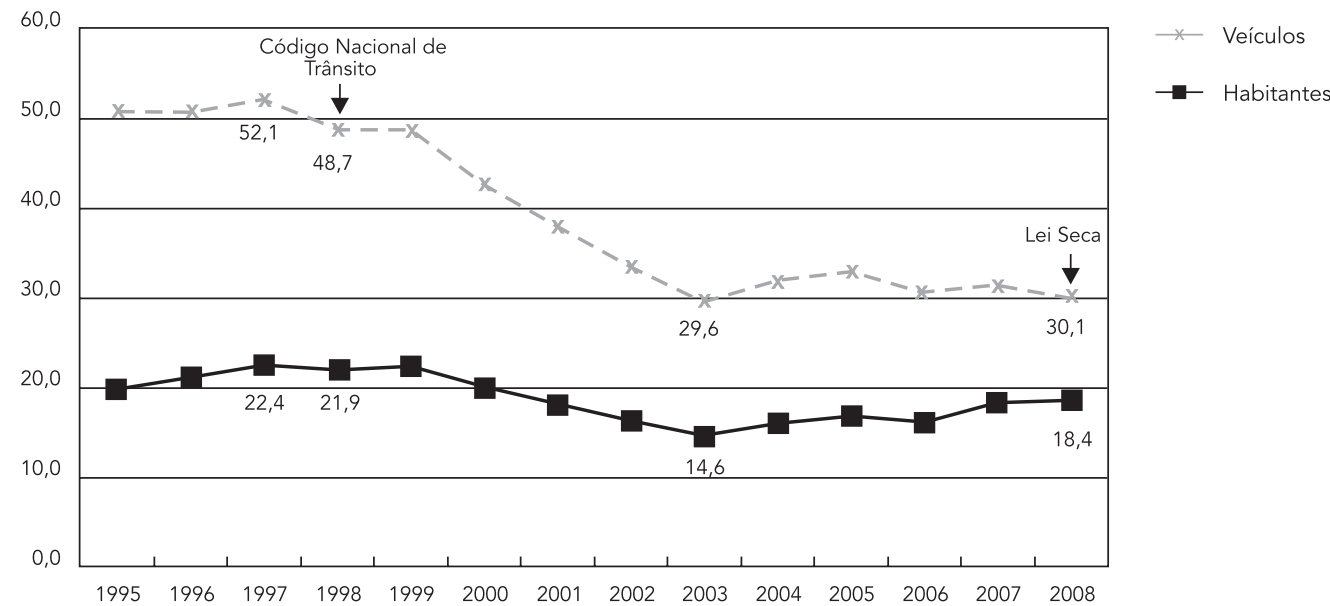

Fonte: Empresa Municipal de Desenvolvimento de Campinas (EMDEC), 1995-2008.

caso dos atropelamentos, os coeficientes de mortalidade masculinos aumentam com o avanço da idade. Em relação aos acidentes entre ocupantes de veículos, de 1997 a 1999, houve tendência decrescente em todas as faixas etárias, sendo esta mais evidente, sobretudo, entre os jovens de 15 a 29 anos, que apresentavam os maiores coeficientes de mortalidade. Em 1997, o risco de morte deste grupo etário era de 60 óbitos em $100 \mathrm{mil}$ homens, tendo declinado para 32 óbitos em 100 mil em 1999. Todavia, após 2006, os valores dos coeficientes aumentaram novamente, sendo superiores a 40 óbitos.

Antes de 2003, a mortalidade proporcional por acidentes de trânsito em veículo não especificado (V89) era muito elevada (superior a 50\%), tendo atingido valores próximos a $10 \%$ em 2008 entre os homens. Por esse motivo, na Figura 3, somente é apresentada a mortalidade por acidentes de trânsito em ocupantes de motocicleta a partir de 2003. A maior mortalidade proporcional em ocupantes de motocicletas foi observada entre os homens de 15 a 39 anos, com valores próximos de $80 \%$ em 2008.

A distribuição espacial dos locais de ocorrência dos acidentes de trânsito fatais em Campinas, construída mediante análise da densidade de pontos com a técnica de Kernel, permite evidenciar áreas de maior concentração dos eventos e, por isso, de potencial interesse. Observa-se que as mortes por acidentes de trânsito encontram- se dispersas em praticamente toda a área urbana e nas rodovias que cortam a cidade (Figura 4). Entre os acidentes fatais ocorridos em rodovias, destaca-se a região próxima à confluência das rodovias Santos Dumont e Bandeirantes e entre os quilômetros 116 e 117 da Rodovia Prof. Zeferino Vaz, com concentração de seis a dez acidentes fatais por quilômetro quadrado. Em relação aos não rodoviários, embora haja dispersão das mortes por acidentes de trânsito no município, é possível identificar duas regiões que registraram densidade mais elevada (6 a 11 óbitos por quilômetro quadrado), sendo uma delas a região central da cidade.

\section{Discussão}

Em Campinas, registrou-se tendência de redução da mortalidade por acidentes de trânsito a partir de 1997. Todavia, como observado na literatura nacional 5, o Código Nacional de Trânsito não teve o impacto esperado, uma vez que a mortalidade diminuiu apenas até o ano de 2005, não atingindo os níveis de países com legislação de trânsito semelhante à brasileira. É preocupante, ainda, o fato dos coeficientes de mortalidade terem sofrido aumento nos anos posteriores a 2005 no Município de Campinas. Este quadro se torna ainda mais dramático quando se avalia a maior disponibilidade de atendimento de emergência 
2a) Vítimas (RT $=3,6)$

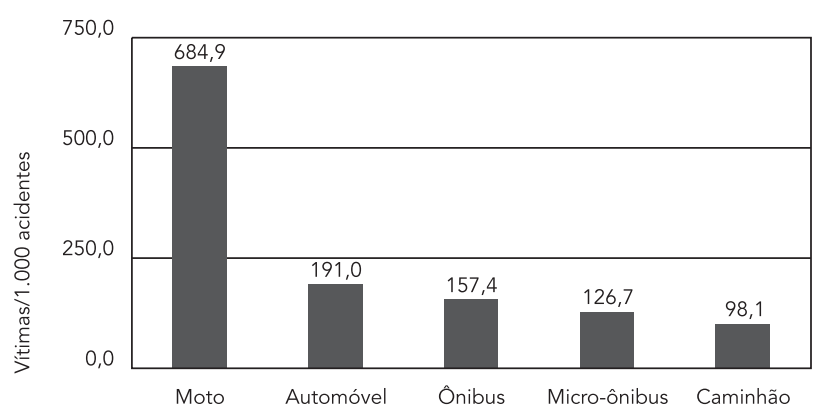

2c) Vítimas fatais $(\mathrm{RT}=7,1)$

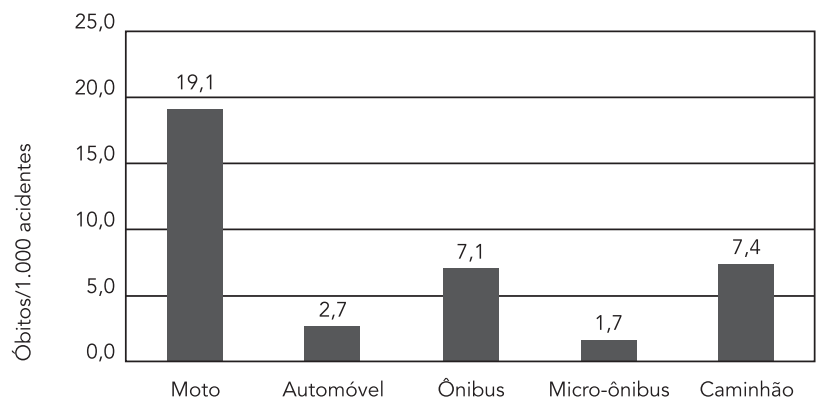

2b) Vítimas pedestres $(R T=3,4)$

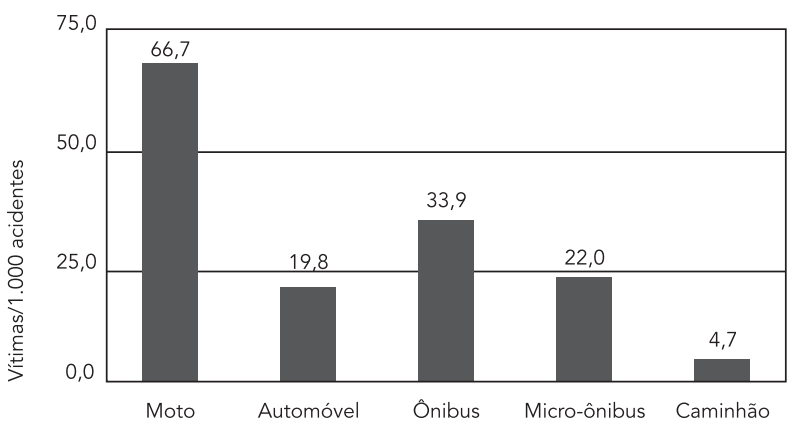

2d) Vítimas fatais pedestres (RT $=6,7)$

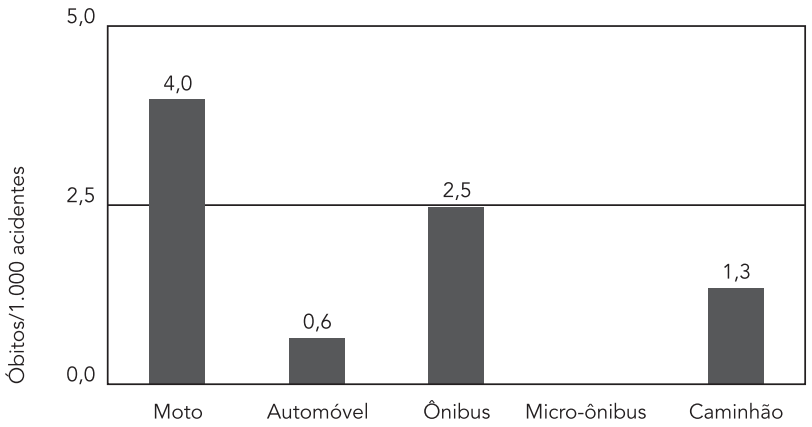

RT: razão entre as taxas de acidentes que envolveram motocicletas em relação aos automóveis. Fonte: Empresa Municipal de Desenvolvimento de Campinas (EMDEC), 2008.

no local da ocorrência, com a maior oferta de serviços do SAMU (Serviço de Atendimento Móvel de Urgência) e do Corpo de Bombeiros 19, bem como o desenvolvimento da tecnologia hospitalar cirúrgica. Para o conjunto das capitais brasileiras, Mello-Jorge et al. 12 também constataram incremento dos coeficientes de mortalidade a partir de 2001 e consideram que este fato pode estar associado à perda de eficiência na fiscalização e aplicação das punições aos infratores.

Não obstante a elevada taxa de motorização de Campinas, da ordem de 61,2 veículos por cem habitantes, a taxa de acidentes por veículo apresentou tendência decrescente entre 1995 e 2008, apesar de oscilações durante o período. Essa diminuição da ocorrência de acidentes de trânsito possivelmente está relacionada à lentidão do trânsito decorrente do aumento da frota 20,21, às atividades promovidas pela EMDEC desde sua criação em 1991 e à implantação do Código Nacional de Trânsito em 1998. Com a municipalização da administração e gerenciamento do trânsito em Campinas, a EMDEC intensificou a fiscalização do trânsito, com a adoção de equipamentos eletrônicos para o controle da velocidade, aplicação de multas aos infratores, monitoramento dos pontos de maior frequência de acidentes para intervenção imediata, como a melhoria na sinalização, entre outras ações, além de ter desenvolvido importantes iniciativas, entre as quais se destacam as campanhas educativas sobre segurança no trânsito 22 .

Entretanto, apesar das intervenções da EMDEC, o percentual de acidentes de trânsito com vítimas cresceu a partir de 2004, possivelmente em decorrência do aumento da frota de motocicletas, à semelhança do que foi observado em outros municípios ${ }^{5}$. Esse maior número de 
Figura 3

Tendência no sexo masculino, segundo faixa etária, dos coeficientes de mortalidade por acidentes em ocupantes de veículos e atropelamentos e da mortalidade proporcional em ocupantes de motocicletas. Campinas, São Paulo, Brasil, 1995-2008.

3a) Ocupantes de veículos

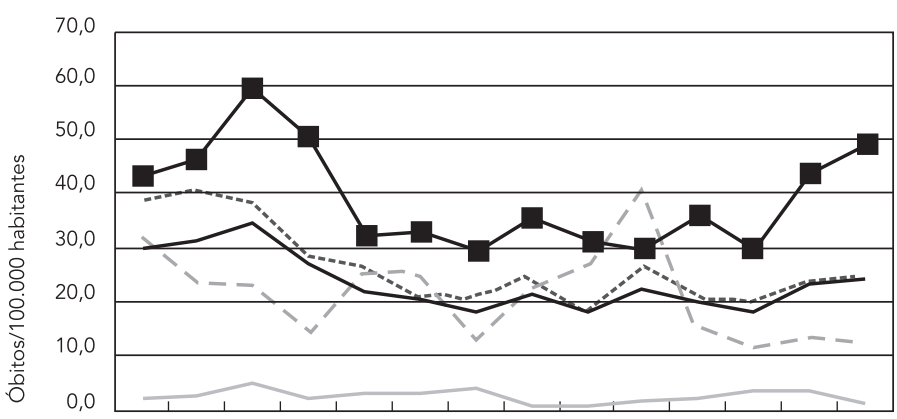

\author{
Menor de 15 anos \\ $\rightarrow-15-29$ anos \\ 30-59 anos \\ --.- 60 ou mais anos \\ - Coeficiente padronizado
}

19951996199719981999200020012002200320042005200620072008

3b) Pedestres

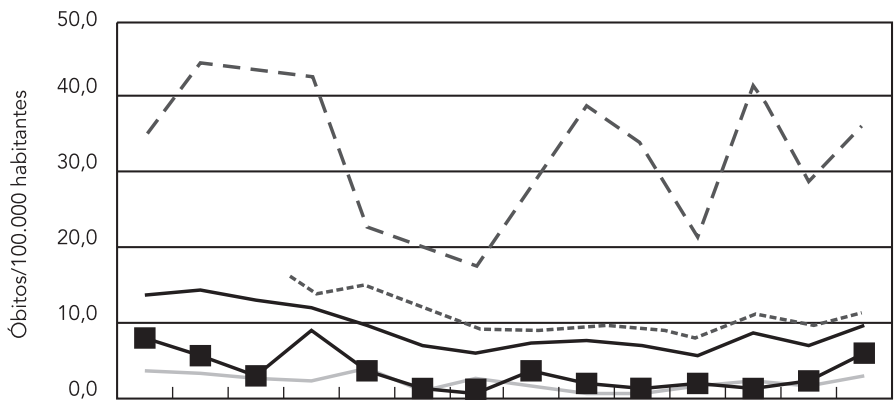

Menor de 15 anos

$\rightarrow-15-29$ anos

30-59 anos

-.- 60 ou mais anos

- Coeficiente padronizado

3c) Ocupantes de motocicletas em relação ao total de ocupantes de veículos (\%)

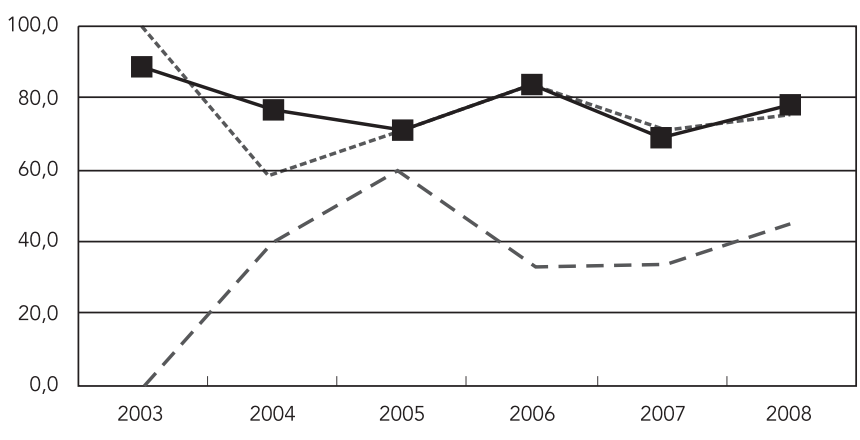

$-15-29$ anos

30-39 anos

-- - 40-59 anos

Fonte: Sistema de Informações sobre Mortalidade (SIM) do Departamento de Informática do SUS

(DATASUS; http://www.datasus.gov.br), 1995-2008. 
Figura 4

Distribuição espacial dos acidentes de trânsito fatais rodoviários e não rodoviários. Campinas, São Paulo, Brasil, 2006-2007.

4a) Rodoviários

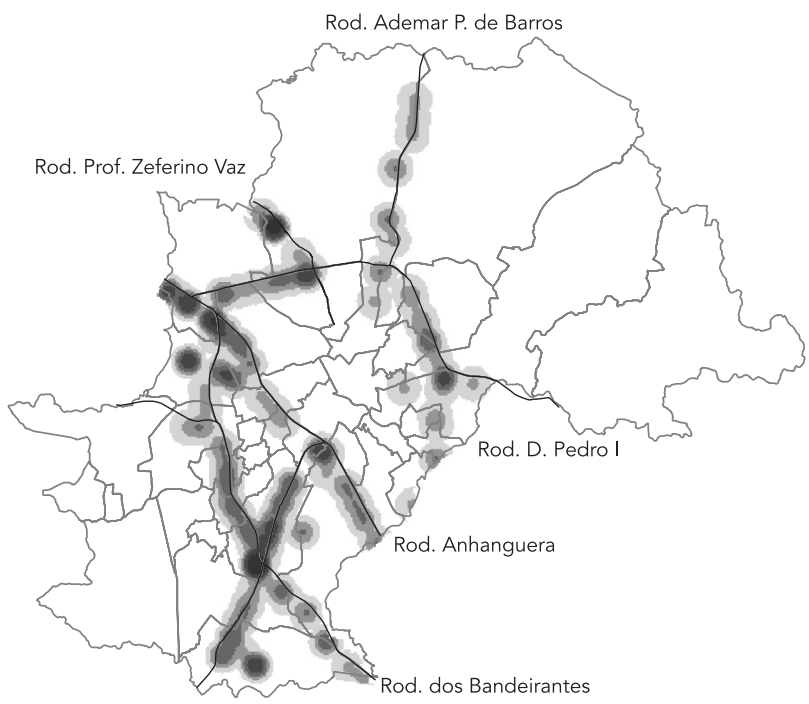

Rod. Santos Dumont

Densidade (óbitos $/ \mathrm{km}^{2}$ )

0,04-0,88

$0,89-1,97$

$1,98-3,43$

$3,44-5,81$

$5,82-10,66$

- Rodovias

Centros de saúde

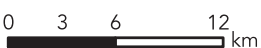

4b) Não rodoviários

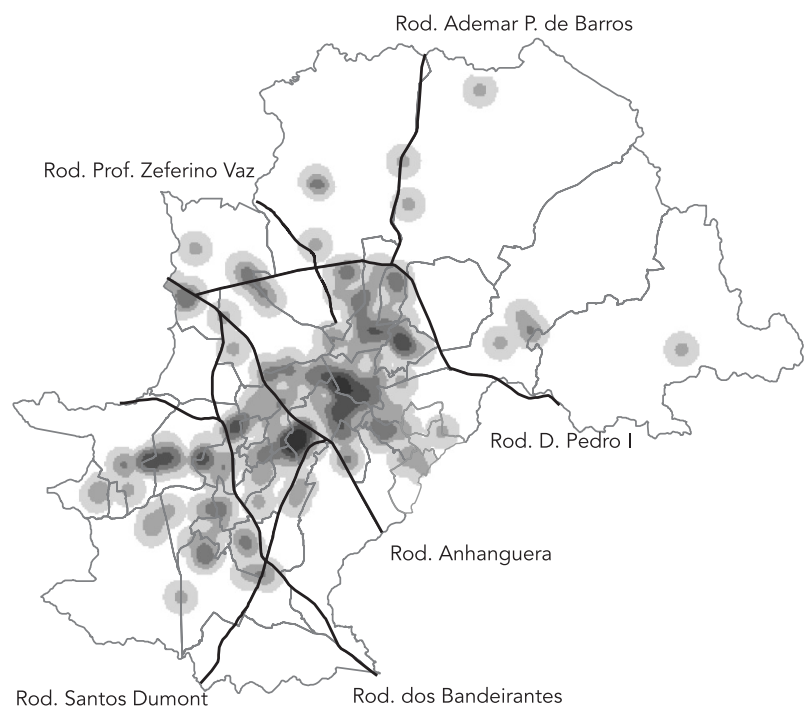

Densidade (óbitos $/ \mathrm{km}^{2}$ )

0,04-0,88

$0,89-1,97$

$1,98-3,43$

$3,44-5,81$

$5,82-10,66$

- Rodovias

Centros de saúde
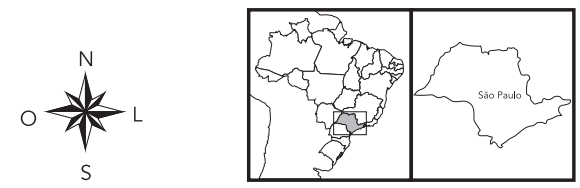

Fonte: Sistema de Informações sobre Mortalidade (SIM) da Secretaria Municipal de Saúde de Campinas (SMS-Campinas), 2006-2007. 
motocicletas foi estimulado pelo marketing 23, uma vez que o apelo à velocidade e à independência 24 é um atrativo importante para jovens, especialmente de poucos recursos financeiros, que podem substituir, assim, o transporte coletivo ineficiente e moroso, além de utilizá-las como instrumentos de trabalho 11,15,17.

Concomitantemente a esse aumento da frota, houve elevação dos coeficientes de mortalidade entre os ocupantes de motocicletas e, ao longo do período estudado, Campinas registrou aumento expressivo dos acidentes de trânsito fatais com ocupantes deste tipo de veículo, passando a representar, em 2008, 49,3\% dos óbitos no trânsito. Os jovens de 15 a 29 anos, sobretudo, do sexo masculino, são os principais envolvidos em acidentes fatais de motocicletas, e a maior incidência desse tipo de morte entre os jovens ilustra a realidade de muitos outros municípios $5,11,12,25$. No Piauí 26, 74,4\% dos condutores de motocicletas tinham entre 15 e 34 anos de idade. Em análise de quatro aglomerações urbanas 27 , os ocupantes de motocicletas, em especial os condutores, apresentaram a maior proporção de acidentes com vítima. Embora a pressão por rapidez exercida por empregadores e clientes de motoboys possa induzir comportamentos de risco na direção do veículo, com consequente aumento de acidentes de trânsito, não foi observada diferença significativa na ocorrência de acidentes de trânsito entre Londrina e Maringá (Paraná), apesar da proporção de pagamento por produtividade ser significativamente maior no primeiro município ${ }^{14}$. Em Campinas, um levantamento não publicado, realizado pela EMDEC, verificou que, de 68 óbitos de motociclistas em 2008, apenas três eram motoboys.

A tendência crescente dos acidentes de trânsito de motociclistas também tem sido observada na Grã-Bretanha 28 , com aumento anual de $4,6 \%$ de internações de acidentados. O corpo do motociclista, exceto a cabeça, protegida por capacete, fica totalmente vulnerável ao impacto, podendo ocorrer lesões múltiplas 28,29 . Diferentemente dos automóveis, as motocicletas não tiveram, no período do estudo, a incorporação de tecnologias para diminuir o impacto das colisões sobre os ocupantes. Além dos comportamentos infratores dos motociclistas, problemas climáticos e nas vias, a instabilidade própria deste veículo facilita derrapagens em curvas e nas conversões, podendo favorecer a ocorrência de acidentes de trânsito ${ }^{30}$. Finalmente, cabe destacar que não têm sido adotadas medidas viárias destinadas a diminuir os acidentes de trânsito, como as faixas segregadas e exclusivas para motocicletas usadas em alguns países asiáticos 17 .
A maior letalidade dos pedestres e dos ocupantes de motocicletas está associada à possibilidade de ambos sofrerem graves traumatismos múltiplos crânio-encefálicos 26,29,31 e de coluna, devido à ausência de proteção. Essa maior letalidade dos pedestres observada em Campinas também foi descrita em Salvador (Bahia) 32. Os dados produzidos pelo Ministério da Saúde 6, da mesma forma que os do município em estudo, também mostraram que o risco de óbito de pedestres aumenta com a idade e que, entre os idosos com 60 anos ou mais, os atropelamentos respondem por cerca de $50 \%$ dos óbitos no trânsito. Em Campinas, o percentual de acidentes com vítimas atropeladas não sofreu aumento entre 1995 e 2008, apesar de, nesse período, ter aumentado a circulação de motocicletas, veículo que mais fere e mata pedestres - este dado também foi encontrado em Pelotas (Rio Grande do Sul) 33. Pode postular-se que as ações educativas e intervenções da EMDEC na sinalização das vias tiveram um impacto positivo, porque, se não houvesse ocorrido o boom de venda de motocicletas, possivelmente a tendência de acidentes fatais por atropelamento teria sido decrescente. Logo, para reduzir os índices de atropelamento, além dos investimentos públicos que já vêm sendo realizados em programas de educação dos pedestres para a travessia segura, no calçamento e sinalização das vias, na construção de passarelas nas rodovias que cortam o município, é essencial concentrar esforços na redução de atropelamentos por condutores de motocicletas. A fiscalização aos motoristas quanto ao respeito às faixas de pedestres, à sinalização do trânsito e às demais normas de trânsito mostram-se como estratégias de grande relevância no combate aos atropelamentos. Ademais, entre os motociclistas, deve ser combatida a sua circulação pela calçada e por outros locais habitualmente restritos aos pedestres.

Em face do acelerado crescimento da frota de motocicletas, dos altos índices de ocorrência de acidentes de trânsito envolvendo este tipo de veículo, da sua gravidade e dos altos coeficientes de mortalidade, principalmente entre os jovens, confirma-se a necessidade das pesquisas investigarem a fundo os diversos aspectos desses agravos 26,34, bem como a urgência em se intensificarem o monitoramento e as ações preventivas, no âmbito tanto da saúde, quanto no de transporte, com o delineamento de intervenções educativas voltadas para cada público-alvo. Pesquisas financiadas pelo governo e as centralizadas no Projeto Viva 19,35, que estão em andamento em diversos municípios do país, permitirão aprofundar os conhecimentos sobre os acidentes, especialmente os atendidos no SUS. 
A dimensão espacial nos estudos de acidentes de trânsito consiste numa importante ferramenta para compreensão da dinâmica desses eventos, indicando áreas prioritárias para a intervenção. Souza et al. 36 explicam a relevância da espacialização dos acidentes de trânsito por esta fornecer subsídios para o planejamento e execução de políticas públicas, aumentando sua eficácia e eficiência na redução e prevenção desses agravos. Com o mapeamento do local de ocorrência de acidentes de trânsito fatais, identificou-se concentração de óbitos em algumas rodovias que cruzam o Município de Campinas. Estes dados sugerem que seria extremamente salutar que a EMDEC atuasse também sobre estas rodovias, garantindo, dessa forma, cobertura integral das intervenções para redução dos acidentes de trânsito em toda a extensão da cidade.

Os dados divulgados por este estudo podem auxiliar não só na definição de ações e de políticas públicas, mas também no fomento dos esforços já empreendidos pelos setores municipais de saúde e de transporte, com vistas à redução dos impactos negativos dos acidentes de trânsito que se manifestam em sequelas psicológicas 37 , em incapacidades temporárias e permanentes $38 \mathrm{e}$ em mortes. Não obstante as campanhas educativas e as diversas parcerias estabelecidas entre a EMDEC e outros órgãos, permanece como desafio a maior conscientização acerca da direção segura entre os condutores, principalmente de motocicletas, aliada à intensificação da fiscalização e à inovação no monitoramento de motociclistas que burlam as câmeras encobrindo a placa do veículo. É importante igualmente salientar que, se o transporte público fosse mais eficiente e ágil e, consequentemente, a venda de motocicletas não tivesse sido fortemente estimulada, a frota destas e os acidentes de trânsito relacionados a elas não teria crescido significativamente.

Também cabe lembrar que tem sido amplamente verificada a associação do comportamento de beber e dirigir com os acidentes de trânsito 39,40,41. Sendo um comportamento associado ao lazer $24,42,43$, é preciso fiscalização ativa para seu controle. A frequência de casos de ingestão de bebida alcoólica entre condutores não diminuiu persistentemente no Município de São Paulo 44 após a introdução da Lei Seca (Lei $n^{\circ}$. 11.705) em junho de 2008, nem em Porto Alegre 45 após o estabelecimento da lei municipal em 2006. Outro novo fator de risco para direção segura é o uso de celular ao dirigir. Mesmo que não existam estudos nacionais, sabe-se que estes e outros aparelhos eletrônicos contribuem para a distração no trânsito e favorecem a ocorrência de acidentes de trânsito, especialmente entre os jovens 46,47 .

Os resultados desta pesquisa apontam que os grupos de maior risco para os acidentes de trânsito são os ocupantes de motocicletas, a população masculina em geral e, sobretudo, os jovens. As ações para conscientização acerca da segurança no trânsito e a promoção de mudança de comportamentos que já são desenvolvidas pelas Secretarias de Transporte e de Saúde devem continuar a ser aprimoradas e especialmente desenvolvidas para a população jovem.

A recente resolução da Assembléia Geral das Nações Unidas 48, em março de 2010, que prioriza ações de segurança no trânsito na década de 2011-2020, estabeleceu o desenvolvimento e implementação de planos com base em cinco eixos: gerenciamento da segurança, desenho e infraestrutura de estradas, segurança dos veículos, comportamentos dos usuários e atendimento aos acidentados. Compartilhando esse chamado da Assembléia Geral das Nações Unidas para aumentar a atenção política sobre a segurança no trânsito, considera-se que, para contribuir na mudança do comportamento infrator, cabe maior agilidade do poder judicial na execução das penalidades por infrações no trânsito, devendo-se, também, evitar procedimentos de anulação de multas das infrações de trânsito. Objetiva-se com isso que as taxas de ocorrências e os coeficientes de mortalidade por acidentes de trânsito diminuam significativamente, de modo a atingir os valores de países com legislação de trânsito semelhante à do Brasil. 


\section{Resumo}

Com o objetivo de descrever a tendência de ocorrência de acidentes de trânsito, sua mortalidade, tipo de veículo envolvido, tamanho da frota e perfil das vítimas em Campinas, São Paulo, Brasil, entre 1995 e 2008, foram estimadas taxas de motorização e ocorrência de acidentes, letalidade, mortalidade proporcional, taxas de mortalidade e razões entre taxas. A frota de motocicletas cresceu $241 \%$. Apesar da queda da letalidade dos acidentes de ocupantes de motos entre 2000 e 2008, esta categoria representou $49,3 \%$ do total de acidentes fatais em vias públicas em 2008. As motos foram responsáveis pelas maiores taxas de atropelamento $(66,7$ atropelados/mil acidentes) e de atropelamentos seguidos de morte (4 óbitos/mil acidentes). Os homens mantiveram risco de morrer no trânsito muito superior ao das mulheres. Nos atropelamentos, predominaram elevadas taxas de mortalidade em idosos; entre os ocupantes de veículos, os mais atingidos foram os de 15 a 29 anos. Na faixa de 15 a 39 anos, entre 2006 e 2008, quase $80 \%$ eram ocupantes de moto. Ações pluri-institucionais devem priorizar a prevenção de acidentes entre motociclistas.

Acidentes de Trânsito; Motocicletas; Mortalidade

\section{Colaboradores}

L. Marín-León participou da elaboração e redação do corpo deste artigo. A. P. Belon colaborou ativamente na estruturação e redação do artigo. M. B. A. Barros participou da revisão de todas as versões do artigo. S. D. M. Almeida e M. C. Restitutti realizaram importantes contribuições à versão final do manuscrito. Todos os autores participaram da análise dos dados.

\section{Agradecimentos}

À Empresa Municipal de Desenvolvimento de Campinas (EMDEC) por compartilhar dados de frota e ocorrência de acidentes de trânsito.

\section{Referências}

1. Departamento de Análise de Situação em Saúde, Secretaria de Vigilância em Saúde, Ministério da Saúde. Mortalidade por acidentes de transporte terrestre no Brasil. Brasília: Ministério da Saúde; 2007. (Série G. Estatística e Informação em Saúde).

2. Organización Panamericana de la Salud. Informe mundial sobre prevención de los traumatismos causados por el tránsito: elementos para la toma de decisiones. Washington DC: Organización Panamericana de la Salud; 2004.

3. World Health Organization. Global status report on road safety: time for action. Geneva: World Health Organization; 2009.

4. Elvik R. The stability of long-term trends in the number of traffic fatalities in a sample of highly motorized countries. Accid Anal Prev 2010; 42: 245-60.

5. Departamento de Análise de Situação em Saúde, Secretaria de Vigilância em Saúde, Ministério da Saúde. Saúde Brasil 2007: uma análise da situação de saúde. Brasília: Ministério da Saúde; 2008. (Série G. Estatística e Informação em Saúde).

6. Departamento de Análise de Situação em Saúde, Secretaria de Vigilância em Saúde, Ministério da Saúde. Saúde Brasil 2006: uma análise da situação de saúde. Brasília: Ministério da Saúde; 2006. (Série G. Estatística e Informação em Saúde).

7. Brasil. Lei $n^{\circ}$. 11.705, de 19 de junho de 2008. Dispõe sobre o consumo de bebida alcoólica por condutor de veículo automotor, e dá outras providências. Diário Oficial da União 2008; 20 jun.

8. Grundy C, Steinbach R, Edwards P, Green J, Armstrong B, Wilkinson P. Effect of $20 \mathrm{mph}$ traffic speed zones on road injuries in London, 1986-2006: controlled interrupted time series analysis. BMJ 2009; 339:b4469.

9. King KA, Vidourek RA, Love J, Wegley S, Alles-White $M$. Teaching adolescents safe driving and passenger behaviors: effectiveness of you hold the key teen driving countermeasure. J Safety Res 2008; 39:19-24.

10. Shope JT. Graduated driver licensing: Review of evaluation results since 2002. J Safety Res 2007; 38:165-75. 
11. Vasconcellos EA. O custo social da motocicleta no Brasil. Revista dos Transportes Públicos 2008; 30/31:127-42.

12. Mello-Jorge MHP, Koizumi MS, Tuono VL. Acidentes de trânsito no Brasil: a situação nas capitais. São Paulo: Associação Brasileira de Medicina do Tráfego; 2008.

13. Veronese AM, Oliveira DLLC. Os riscos dos acidentes de trânsito na perspectiva dos moto-boys: subsídios para a promoção da saúde. Cad Saúde Pública 2006; 22:2717-21.

14. Silva DW, Andrade SM, Soares DA, Soares DFPP, Mathias TAF. Perfil do trabalho e acidentes de trânsito entre motociclistas de entregas em dois municípios de médio porte do Estado do Paraná, Brasil. Cad Saúde Pública 2008; 24:2643-52.

15. Silva DW, Andrade SM, Soares DA, Nunes EFPA, Melchior R. Condições de trabalho e riscos no trânsito urbano na ótica de trabalhadores motociclistas. Physis (Rio J.) 2008; 18:339-60.

16. Diniz EPH, Assunção AA, Lima FPA. Prevenção de acidentes: reconhecimento das estratégias operatórias dos motociclistas profissionais como base para a negociação de acordo coletivo. Ciênc Saúde Coletiva 2005; 10:905-16.

17. Holz RF, Lindau LA, Nodari CT. Desafios impostos por motociclistas em áreas urbanas: o caso brasileiro. In: XVI Pan-American Conference of Traffic and Transportation Engineering and Logistics (PANAM). Lisboa: Centro de Sistemas Urbanos e Regionais, Instituto Superior Técnico, Universidade Técnica de Lisboa; 2010. p. 1-11.

18. Ministério da Saúde. Introdução à estatística espacial para a saúde pública. Brasília: Ministério da Saúde; 2007. (Série B. Textos Básicos de Saúde. Série Capacitação e Atualização em Geoprocessamento em Saúde, 3).

19. Departamento de Análise de Situação em Saúde, Secretaria de Vigilância em Saúde, Ministério da Saúde. Viva: vigilância de violências e acidentes, 2006 e 2007. Brasília: Ministério da Saúde; 2009.

20. Kilsztajn S, Silva CRL, Silva DF, Michelin AC, Carvalho AR, Ferraz ILB. Taxa de mortalidade por acidentes de trânsito e frota de veículos. Rev Saúde Pública. 2001; 35:262-8.

21. Gawryszewski VP, Mello-Jorge MHP. Mortalidade violenta no Município de São Paulo nos últimos 40 anos. Rev Bras Epidemiol 2000; 3:50-69.

22. Queiroz MS, Oliveira PCP. Acidentes de trânsito: uma visão qualitativa no Município de Campinas, São Paulo, Brasil. Cad Saúde Pública 2002; 18:1179-87.

23. Pinsky I, Pavarino Filho RV. The promotion of alcoholic beverage consumption and traffic speed in Brazil considerations on the advertising of two public health problems. Rev Psiquiatr Rio Gd Sul 2007; 29:110-8.

24. Marín-León L, Vizzotto MM. Comportamentos no trânsito: um estudo epidemiológico com estudantes universitários. Cad Saúde Pública 2003; 19: 515-23.

25. Andrade SM, Mello-Jorge MHP. Acidentes de transporte terrestre em município da Região Sul do Brasil. Rev Saúde Pública 2001; 35:318-20.
26. Santos AMR, Moura MEB, Nunes BMVT, Leal CFS, Teles JBM. Perfil das vítimas de trauma por acidente de moto atendidas em um serviço público de emergência. Cad Saúde Pública 2008; 24:1927-38.

27. Instituto de Pesquisa Econômica Aplicada. Pesquisa de acidentes de trânsito nas aglomerações urbanas de Belém, Recife, São Paulo e Porto Alegre. Brasília: Instituto de Pesquisa Econômica Aplicada; 2004.

28. Lyons RA, Ward H, Brunt H, Macey S, Thoreau R, Bodger OG, et al. Using multiple datasets to understand trends in serious road traffic causalities. Accid Anal Prev 2008; 40:1406-10.

29. Sousa RMC, Regis FC, Koizumi MS. Traumatismo crânio-encefálico: diferenças das vítimas pedestres e ocupantes de veículos a motor. Rev Saúde Pública 1999; 33:85-94.

30. Clarke DD, Ward P, Bartle C, Truman W. The role of motorcyclist and other driver behavior in two types of serious accident in the UK. Accid Anal Prev 2007; 39:974-81.

31. Gawryszewski VP, Coelho HMM, Scarpelini S, Zan R, Mello-Jorge MHP, Rodrigues SEM. Perfil dos atendimentos a acidentes de transporte terrestre por serviços de emergência em São Paulo, 2005. Rev Saúde Pública 2009; 43:275-82.

32. Oliveira ZC, Mota ELA, Costa MCN. Evolução dos acidentes de trânsito em um grande centro urbano, 1991-2000. Cad Saúde Pública 2008; 24:364-72.

33. Barros AJD, Amaral RL, Oliveira MSB, Lima SC, Gonçalves EV. Acidentes de trânsito com vítimas: sub-registro, caracterização e letalidade. Cad Saúde Pública 2003; 19:979-86.

34. Davantel PP, Pelloso SC, Carvalho MDB, Oliveira NLB. A mulher e o acidente de trânsito: caracterização do evento em Maringá, Paraná. Rev Bras Epidemiol 2009; 12:355-67.

35. Morais Neto OL, Malta DC, Silva MMA. Promoção à saúde e vigilância de violências: efetividade e perspectivas. Ciênc Saúde Coletiva 2009; 14:1638.

36. Souza VR, Cavenaghi S, Alves JED, Magalhães MAFM. Análise espacial dos acidentes de trânsito com vítimas fatais: comparação entre o local de residência e de ocorrência do acidente no Rio de Janeiro. Rev Bras Estud Popul 2008; 25:353-64.

37. Cavalcante FG, Morita PA, Haddad SR. Sequelas invisíveis dos acidentes de trânsito: o transtorno de estresse pós-traumático como problema de saúde pública. Ciênc Saúde Coletiva 2009; 14:1763-72.

38. Bampi LNS, Guilhem D, Lima D. Qualidade de vida em pessoas com lesão medular traumática: um estudo com o WHOQOL-bref. Rev Bras Epidemiol 2008; 11:67-77.

39. Teigen A, Savage M. Lawmakers hope new technology could mean the end to drunken driving. State Legislatures 2009; 35:26-9.

40. Modelli MES, Pratesi R, Tauil PL. Alcoolemia em vítimas fatais de acidentes de trânsito no Distrito Federal, Brasil. Rev Saúde Pública 2008; 42:350-2.

41. Mascarenhas MDM, Malta DC, Silva MMA, GazalCarvalho C, Monteiro RA. Consumo de álcool entre vítimas de acidentes e violências atendidas em serviços de emergência no Brasil, 2006 e 2007. Ciênc Saúde Coletiva 2009; 14:1789-96. 
42. Marín L, Queiroz MS. A atualidade dos acidentes de trânsito na era da velocidade: uma visão geral. Cad Saúde Pública 2000; 16:7-21.

43. Ramos P, Diez E, Pérez K, Rodriguez-Martos A, Brugal MT, Villalbi JR. Young people's perceptions of traffic injury risks, prevention and enforcement measures: a qualitative study. Accid Anal Prev 2008; 40:1313-9.

44. Moura EC, Malta DC, Morais Neto OL, Penna GO, Temporão JG. Direção de veículos motorizados após consumo abusivo de bebidas alcoólicas, Brasil, 2006 a 2009. Rev Saúde Pública 2009; 43:891-4.

45. De Boni R, Leukefeld C, Pechansky F. Young people's blood alcohol concentration and the alcohol consumption, Brazil. Rev Saúde Pública 2008; 42:1101-4.
46. Hosking SG, Young KL, Regan MA. The effects of text messaging on young drivers. Hum Factors 2009; 51:582-92.

47. Jacobson PD, Gostin LO. Reducing distracted driving: regulation and education to avert traffic injuries and fatalities. JAMA 2010; 303:1419-20.

48. United Nations. General Assembly adopts text proclaiming decade of action for road safety (20112020), aimed at reducing traffic-related deaths, injuries. Texts on end of Second World War, cooperation with regional body also passed. http://www. un.org/News/Press/docs/2010/ga10920.doc.htm (acessado em Mai/2010).

Recebido em 16/Nov/2010

Versão final reapresentada em 27/Jun/2011

Aprovado em 15/Set/2011 